\title{
GEOLOGIA E EVOLUÇÃO GEOLÓGICA DA REGIÃO DE EMBU-GUAÇU - PARELHEIROS, SP
}

\begin{abstract}
GEOLOGY AND GEOLOGICAL EVOLUTION OF THE EMBU-GUAÇU-PARELHEIROS REGION, SP. The area considered by this study comprehends a polygon of approximately $480 \mathrm{~km}^{2}$ in the southern portion of the Grande São Paulo. Two Precambrian units, intruded by the Embu-Guacu, Parelheiros and Colônia Granites were characterized in mis area. These Precambrian sequences, ascribable to the Pilar complex of the Açngui Group, are represented by a suit informally called "Santa Rita" and by a set of sericite schists and phyllites. At least three ductile deformational events $(\mathrm{F} 1, \mathrm{~F} 2, \mathrm{P} 3)$ are printed over the reliquiar bedding in the metassedimentary sequences through folds and foliations, as well as a ruptile one $\left(\mathrm{F}_{4}\right)$ through mylonitic and cataclastíc textures. An episode of regional metamorphism $\left(\mathrm{M}_{1}\right.$, compatible with amphibolite fades conditions, developed contemporaneously to $\mathrm{F}_{1}$ and in conditions prekinematic to $\mathrm{F}_{2}$. The cristallization of muscovite, fibrolite and tourmaline, synkinematic to late with regard to $\mathrm{Fa}$, was due to metassomatic transformations $\left(\mathrm{M}_{2}\right)$ on a regional scale wich followed me emplacement of the granitic bodies. The cooling wich followed mis period promoted the adjustment of the mineralogical assemblages produced during $\mathrm{M}_{1}$ to new conditions, mus defining the retrometamorphic episode (Ma). At last, there was a restricted event of cataclastic metamorphism (NT, , related to movements along the fault zones. Values of $612 \mathrm{Ma}$ and $550 \mathrm{Ma}$ obtained for the Embu-Guacu Granite and a pegmatite associated to it, are considered to represent the age of formation of these rocks. For "Santa Rita" schists, age determinations furnished $750 \mathrm{Ma}$.
\end{abstract}

Keywords: Geology, Great São Paulo City, Precambrian, Pilar Complex, Açungui Group, Granite of Parelheiros, Granite of Embu-Guacu, Granite of Colônia, structures, metamorphism, geochronology.

\begin{abstract}
RESUMO A área considerada por este estudo compreende um polígono de aproximadamente 480 $\mathrm{km}^{2}$, situado na porção sudeste da Grande São Paulo. Foram reconhecidas, na área, duas unidades pré-cambrianas, intrudidas pelos Granites de Embu-Guaçu, Parelheiros e Colônia. Estas sequiências pré-cambrianas, referfveis ao Complexo Pilar do Grupo Açungui, são representadas por uma suíte informalmente denominada "Santa Rita" e por um conjunto de sericita xistos e fillhos. Pelo menos três eventos de deformação dtfctil (F1, F2, F3) estão impressos sobre o acamamento reliquiar dos metassedimentos, sob a forma de dobras e foliações, bem como um rfptil ( $\mathrm{F} 4$, por meio de texturas cataclásticas e miloníticas. Um episódio de metadeveu-se ã transformações metassomáticas (M2) em escala regional, posteriores à colocação dos corpos graníticos. $\mathrm{O}$ resfriamento que se seguiu a este período promoveu a adaptação de assembléias produzidas durante $\mathrm{M}_{1}$ a novas condiçôes, definindo, assim, o evento de metamorfismo retrógrado $\left(\mathrm{M}_{3}\right)$. Finalmente, relacionado à movimentacão ao longo das zonas de falha, há um evento dinâmico (M) Valores de $612 \mathrm{Ma} e$ $550 \mathrm{Ma}$, obtidos para o Granito de Embu-Guaçu e para um pegmatite a ele associado, foram considerados como as idades de formação destas rochas. Para os xistos "Santa Rita", determinações realizadas forneceram o valor de $750 \mathrm{Ma}$, interpretada como a idade do metamorfismo destas rochas.
\end{abstract}

Palavras-chaves: Geologia, Grande São Paulo, Pré-Cambriano, Complexo Pilar, Grupo Açungui, Granito de Parelheiros, Granito de Embu-Guaçu, Granito de Colônia, estruturas, metamorfismo, geocronologia.

INTRODUÇÃO Este trabalho foi motivado, principalmente, pela escassez de conhecimento acerca das seqüências metassedimentares paulistas e, especialmente, daquelas situadas entre a região do Vale do Ribeira e a cidade de São Paulo. Isto tem dificultado correlações tanto com unidades razoavelmente conhecidas no Paraná, quanto com aquelas descritas a norte da capital paulista.

Entre os poucos estudos realizados nesta área, destacam-se os de Coutinho (1972) e Hasui \& Sadowski (1976) que, mapeando estas seqüências, atribuíram-nas ao Grupo Açungui (correlacionável ao São Roque, Coutinho 1972), então divididas em dois complexos litológicos: um composto essencialmente por ectinitos e denominado Pilar e outro, migmatítico, denominado Embu (Hasui \& Sadowski 1976).

LOCALIZAÇ̃̃O DA ÁREA A área estudada, um polígono regular de aproximadamente $480 \mathrm{~km}^{2}$, inscrito nas folhas topográficas (1:50.000) de Embu-Guaçu e Riacho Grande, localiza-se ao sul da cidade de São Paulo e abrange parte dos municípios de Itapecirica da Serra, Embu-Guaçu, São Paulo e Juquitiba (Fig. 1).

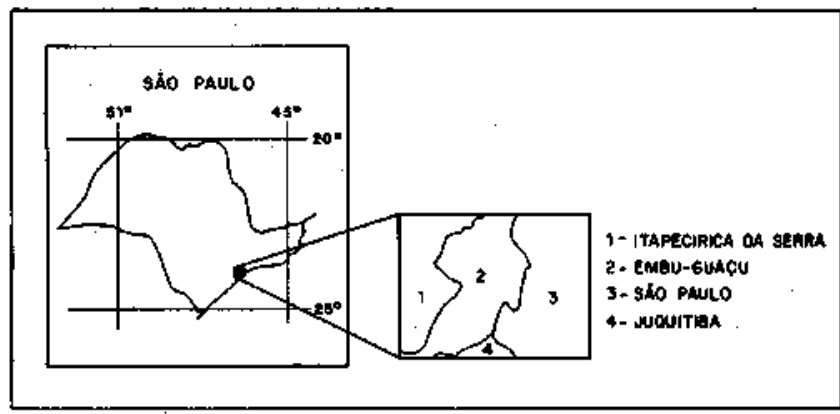

Figura I - Localização da area mapeada

Figure 1 - Locatization of mipped area

\footnotetext{
* Departamento de Mineralogia e Petrologia, Instituto de Geociências, Universidade de São Paulo, Caixa Postal 20899, CEP 01498, São Paulo, SP, Brasil

** Agrupamento de Petrologia, Divisão de Geologia e Recursos Minerais, Instituto de Pesquisas Tecnológicas do Estado de São Paulo S.A. - IPT, Caixa Postal 7141, CEP 01051, São Paulo, SP, Brasil
} 
GEOLOGIA LOCAL A geologia local consiste em seqüências metamórficas pré-cambrianas representadas por rochas dos fácies xisto verde e anfibolito e pelos granites de Embu-Guaçu, Parelheiros e Colônia, parcialmente cobertos por sedimentos terciários, correlacionáveis aos da Bacia de São Paulo, e aluviões quaternários (Fig. 2).

Rochas Metamórficas Distinguem-se dois conjuntos metassedimentares, diferenciados, principalmente, pelo grau metamórfico e pela presença de intercalaçõeslitológicas diversas. $\mathrm{O}$ primeiro, informalmente denominado "unidade dos xistos Santa Rita", é predominante e tem suas melhores exposições na estrada que liga Santa Rita a Embu-Guaçu; caracteri- za-se pela alternância rítmica de estratos decimétricos de micaxistos e quartzo xistos, freqüentemente injetados por pegmatites centimétricos e decamétricos, concordantes ou não (Foto 1).

Concordantemente, ocorrem níveis decimétricos de rochas anfibolíticas, cálcio-silicáticas e metaultramáficas, que permitem a divisão da unidade em domínios litológicos a partir da freqüência com que estas intercalações se distribuem.

Assim, o domínio I, bem representado nos arredores de Santa Rita e Engenheiro Marsilac, caracteriza-se pela presença de anfibolitos, rochas metaultramáficas e cálcio-silicáticas em níveis concordantes com a estratificação reliquiar, dobrados e boudinados (Foto 2).

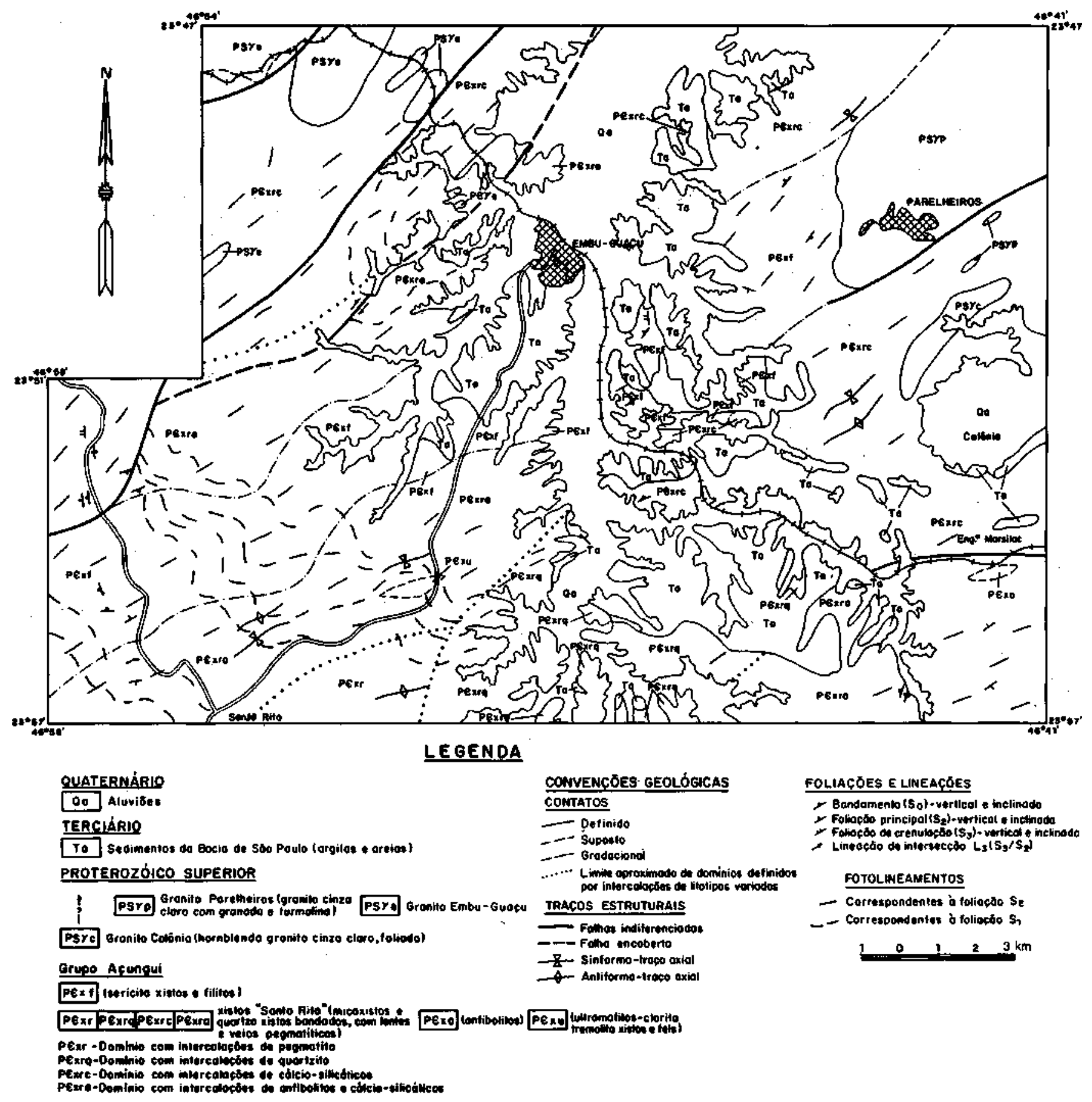

Figura 2 - Mapa geológico da região de Embu-Guaçu - Parelheiros (simplificado de Vieira 1989) Figure 2 - Geologic map of the Embu-Guaçu - Parelheiros Region (simplified from Vieira 1989) 


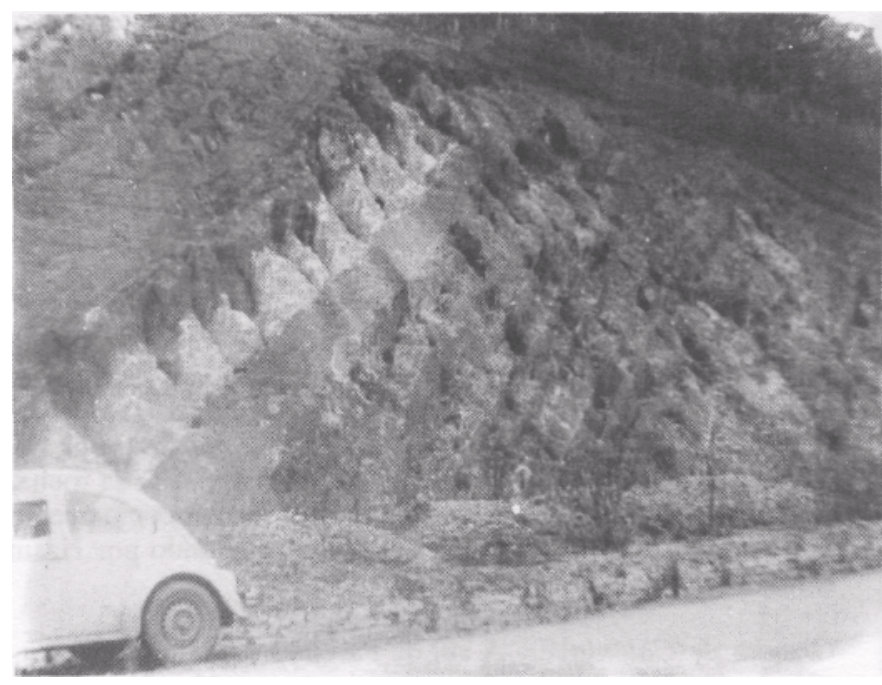

Foto 1 - Afloramento de micaxistos e quartzo xistos pertencentes à unidade "Santa Rita", evidenciando a estratificação reliquiar

Photo 1 - Outcrop of mica schists and quartz schists related to the "Santa Rita" Unit, exhibiting reliquiar stratification

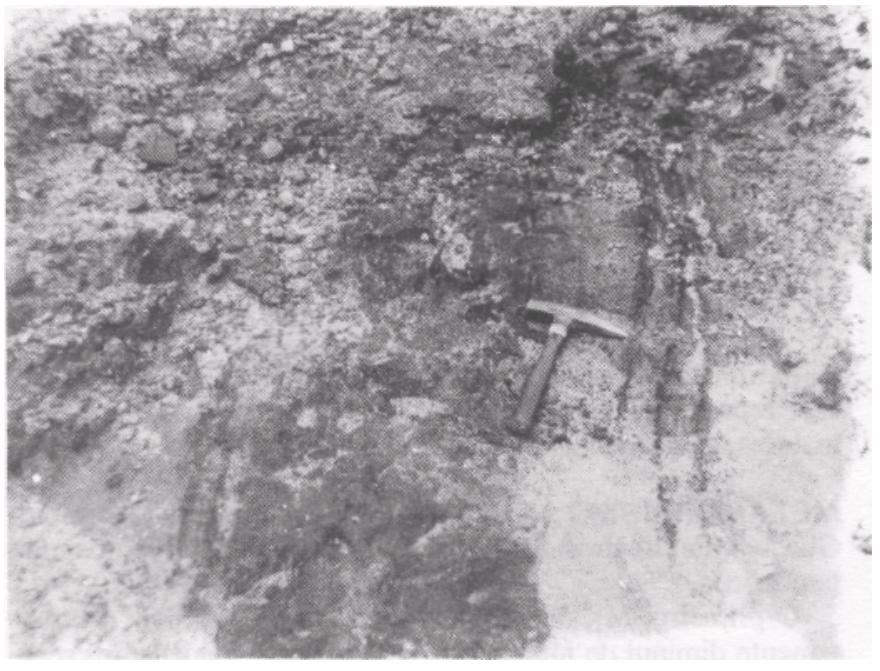

Foto 2 - Afloramento típico da unidade "Santa Rita", nele é possivel observar níveis de anfibolitos/metaultramafitos (escuros)

Photo 2 - Typical outcrop of the "Santa Rita" Unit, where it is posible to observe levels of amphibolites/metaultramafites (dark)

Os xistos são moscovita- biotita- quartzo xistos de granulação média, com cianita, estaurolita, granada, sillimanita e turmalina. Possuem estrutura xistosa, finamente laminada, na qual faixas escuras, compostas por biotita, cianita, sillimanita, estaurolita, apatita e titanita, intercalam-se a outras mais claras, quartzosas.

Além da moscovita concordante com a foliação principal, há porfiroblastos discordantes, atribuídos a um evento de cristalização tardio à deformação. Esses megacristais contêm freqüentes inclusões de opacos, biotita, cianita, sillimanita prismática e fibrosa ("fibrolita") - que ocorre como ondas ou fibras sem orientação definida. A turmalina cresce orientada no plano da xistosidade da rocha, originando uma lineação mineral.

Os quartzo xistos são estrutural e texturalmente bastante semelhantes aos micaxistos, dos quais se diferenciam, basica- mente, por intermédio da mineralogia, na qual são destaques a grande quantidade de quartzo, a presença de plagioclásio, ainda que pouco freqüente, e a ausência de cianita, estaurolita e sillimanita.

As rochas cálcio-silicáticas constituem-se de quartzo, diopsídio, anfibólio (tremolita-actinolita), epídoto, granada, plagioclásio (bytownita), titanita, calcita, zircão e apatita, em grãos eqüidimensionais, finos, arranjados em uma estrutura isótropa e textura granoblástica, com tendência à poligonização.

Próximo à estação ferroviária de Engenheiro Marsilac, as rochas anfibolíticas atingem dimensões métricas, constituindo um corpo quase inteiramente bauxitizado. Nos raros afloramentos frescos, a rocha é estruturalmente isótropa, com textura de recristalização granoblástica, poligonal, com arranjo de grãos médios de diopsídio, hornblenda, andesina e opacos eqüidimensionais, euédricos.

Os metaultramafitos foram encontrados a aproximadamente $4 \mathrm{~km}$ a nordeste de Santa Rita, como blocos decimétricos pouco alterados ou como saprólito verde e azul-arroxeado. Frescos, são verde-escuros, isótropos e levemente blastoporfiróides ou porfiroblásticos, com megacristais anédricos de cummingtonita imersos em uma matriz treliçada, eqüigranular fina, constituída por clorita magnesiana, anfibólio e opacos esqueléticos como acessórios. Estão pouco recristalizados e raramente exibem foliação.

Embora as relações de campo, a estrutura e a textura destas rochas não sejam definitivamente diagnosticas, parece lógico supor que tenham se originado na forma de sills, ainda que a hipótese de representarem porções de derrames deformados e transpostos não possa ser descartada.

O domínio II compreende as seqüências situadas nos arredores dos grani tos de Embu-Guaçu, Parelheiros e Colônia, e é caracterizado pela maior freqüência das intercalações de rochas cálcio-silicáticas nos xistos rítmicos "Santa Rita".

Mais próximo das intrusões, é comum um aumento de granulação dos xistos e obliteração parcial de sua foliação, ocasionada por sua recristalização em condições estáticas e promovida por aumento de temperatura associado às intrusões. A grande quantidade de veios pegmatíticos conferem aos xistos semelhança a migmatitos.

No domínio III, os níveis de rochas anfibolíticas, metaultramáficas e cálcio-silicáticas dão lugar a quartzitos e metarenitos puros e impuros, que afloram como blocos decimétricos e métricos a sul de Cipó. São rochas finas e grossas, com predominância de quartzo anédrico, eqüidimensional, deformado, com forte extinção ondulante e sinais de recuperação. A estrutura é isótropa e a textura, granoblástica a poligonal. Nos tipos mais puros, em que o quartzo representa até $95 \%$ da rocha, encontram-se moscovita e turmalina como acessórios. Nos impuros, o quartzo representa $40 \%$ a $50 \%$ da rocha; o restante corresponde a sericita (pelo menos em parte gerada por intemperismo), moscovita, turmalina, zircão e titanita substituída por leucoxênio.

Os pegmatitos, onipresentes em todos os domínios, são bastante expressivos a leste de Santa Rita, caracterizando o domínio IV; são constituídos por feldspato, moscovita, quartzo e turmalina centimétricos, como minerais principais, e por quantidades menores de biotita e zircão.

Cortando toda a unidade dos xistos "Santa Rita" e mantendo com ela contatos transicionais, ocorre a unidade dos sericita xistos e filitos, que se diferencia da anterior especialmente pelo aspecto sedoso, granulação fina e laminação estreita de suas rochas, e pela ausência de intercalações (Foto 3).

O estudo petrográfico detalhado dessas rochas é prejudicado pelo seu avançado grau de alteração, que impede a obtenção de amostras suficientemente compactas para a laminação. Ainda assim, seções delgadas obtidas mediante a impregnação das amostras com verniz, revelaram um material profundamente transformado por processos supérgenos. Nada resta 


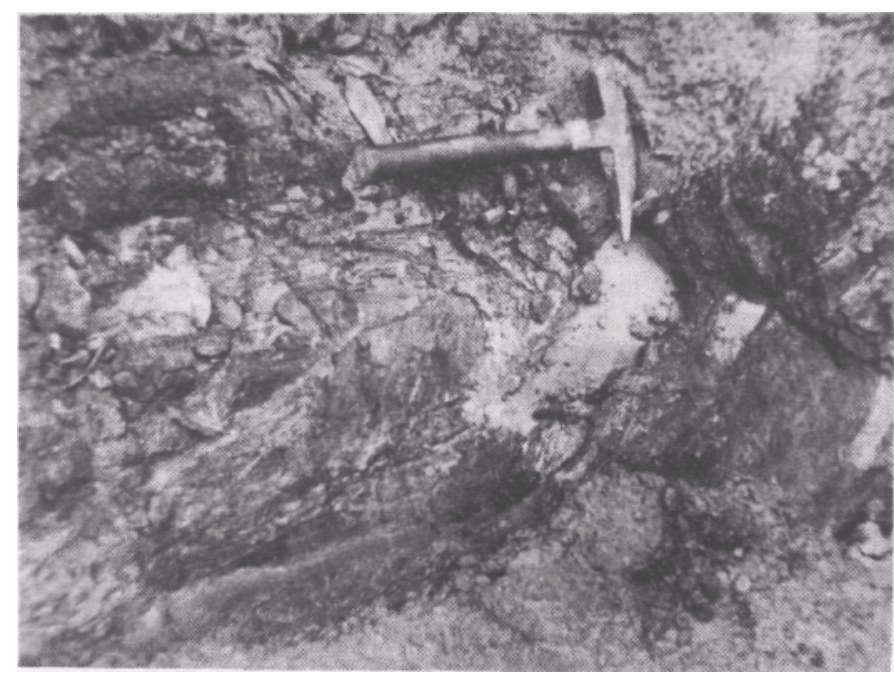

Foto 3 - Afloramento de sericita xistos efilitos, mostrando laminação milimétrica subparalela ao plano do maneio Photo 3 - Sericita schist and philite outcrop, showing thin lamination subparallel to the plane of the hammer

da assembléia metamórfica, a não ser porfiroblastos totalmentes substituídos por argilo-minerais e óxidos e hidróxidos de ferro, que mascaram qualquer característica do mineral original, impedindo seu reconhecimento. No entanto, há indícios de granada e o fato de não terem sido encontrados minerais resistentes ao intemperismo, como sillimanita, sugere sua ausência na rocha sã.

Rochas Granfticas Granito de Parelheiros No extremo nordeste da área mapeada, invadindo tanto os sericita xistos e filitos quanto os xistos "Santa Rita", encontra-se o Granito de Parelheiros, um stock alongado segundo NE-SW, à mesma direção dos xistos encaixantes. Os contatos com os metassedimentos são concordantes a noroeste e por falha a sudeste, evidenciada pela presença de milonitos.

É um granito cinzento-esverdeado, mesocrático, porfirítico, com megacristais euédricos de feldspato alcalino, imersos em matriz fanerítica média a grossa, levemente orientada.

Localmente, a rocha é mais eqüigranular e leucocrática, tendo moscovita, granada e turmalina como acessórios característicos. A textura é granular hipidiomórfica, definida por quartzo, feldspato potássico e plagioclásio, em proporções semelhantes como minerais essenciais, e por biotita, titanita, opacos, zircão, allanita, moscovita, turmalina e granada como acessórios que constituem de $10 \%$ a $20 \%$ da rocha.

Nas bordas, o granito adquire aspecto gnáissico, com estrutura anisótropa, fortemente orientada, e textura grano-lepidoblástica, com bandamento milimétrico.

É um granito sensu stríctu, atribuído por Hasui et al. (1978) ao fácies Cantareira e interpretado por Wernick (1984) como um corpo híbrido, cálciò-alcalino de média profundidade.

As relações de contato e estruturais caracterizam-no como um granito autóctone, sin a tardi-tectônico.

Granito de Embu-Guaçu A noroeste da cidade de EmbuGuaçu afloram pequenos corpos graníticos alongados e concordantes com a estruturação regional. São todos mineralógica e estruturalmente bastante semelhantes e devem compor uma ocorrência maior, parcialmente encoberta pelos xistos "Santa Rita".

Este granito é cinzento, mesocrático, eqüigranular, médio e predominantemente isótropo. Contém freqüentes encraves básicos com biotita e é cortado por pegmatites delgados.
Nas porções marginais do corpo, reconhece-se uma foliação que faz com que a rocha seja melhor caracterizada como um gnaisse. Uma dessas porções, situada imediatamente a NW de Embu-Guaçu, foi mapeada como um corpo independente (Morgental et al. 1975, Hasui \& Sadowski 1976, Hasui et al. 1978, Bistrichi 1982 e Landim et al. 1984). No entanto, como sua assembléia mineral não é diferente daquela encontrada nas porções mais isótropas do maciço, preferiu-se admiti-la como fácies de uma intrusão maior.

Ao microscópio, este granito é quase isótropo, levemente orientado, com textura granular hipidiomórfica e granulação fina a grossa. É constituído essencialmente por quartzo, feldspato potássico e plagioclásio, e por biotita, allanita, opacos, zircão e epídoto que, em conjunto, representam $15 \%$ da rocha.

É um granito sensu stríctu, sin a tardi-cinemático ao evento que gerou a foliação principal dos xistos, atribuído por Hasui et al. (1978) ao fácies Cantareira.

Granito de Colônia A sul de Parelheiros, junto à depressão de Colônia, encontra-se um corpo granítico pequeno e alongado segundo ENE, à mesma direção das estruturas das encaixantes.

Este corpo, descrito por Coutinho (1980) como um granodiorito e por Wernick (1984) como tonalito; foi redefinido por Vieira (1989) como um mela-granito sensu-strictu, com base em estudos petrográficos e é, desde então, denominado "Granito de Colônia".

Microscopicamente, é uma rocha levemente anisótropa, com textura granular hipidiomórfica e granulação seriada fina a média-grossa; é constituída por quartzo, microclínio e plagioclásio, como minerais essenciais, além de titanita, zircão, apatita, allanita e epídoto, como acessórios.

Coberturas Terciárias As coberturas terciárias, cuidadosamente mapeadas por Coutinho (1980), correspondem as argilas variegadas, correlatas às da Bacia de São Paulo.

Sedimentos Quaternários Os sedimentos quaternários são representados pelas argilas e areias depositadas pelos maiores cursos de água da região.

METAMORFISMO As rochas da região de EmbuGuaçu - Parelheiros foram afetadas por quatro eventos metamórficos.

$\mathrm{O}$ primeiro, $\mathrm{M}_{1}$, de caráter regional e progressivo, aparentemente diminui de intensidade em direção a unidade dos sericita xistos e filitos. Nos xistos "Santa Rita", as paragêneses, tanto dos xistos quanto das rochas cálcio-silicáticas, são compatíveis com o fácies anfibolito, tendo sido geradas em épocas sin a tardi-cinemáticas à primeira fase de deformação.

O segundo, M2, também de expressão regional, está materializado por moscovita, sillimanita fibrosa e turmalina discordantes da foliação principal, cuja gênese foi atribuída por Vieira (1989) a um provável processo metassomático extenso, promovido pela ação de soluções residuais da atividade magmática intensa durante o Brasiliano.

A saussuritízação dos feldspatos, a cloritização das granadas e biotitas e as substituições do plagioclásio por epídoto e de diopsídio por tremolita, refletem a adaptação das assembléias de pressão e temperaturas elevadas, produzidas durante o primeiro episódio de metamorfismo, a condições mais brandas, caracterizando o metamorfismo retrógrado Ma.

Finalmente, o último evento, $\mathrm{M}$ corresponde a transformações texturais e estruturais promovidas pela movimentação ao longo de zonas de falha.

ESTRUTURAS É reconhecida, regionalmente na área estudada, uma foliação que ao microscópico pode ser caracterizada como uma clivagem de crenulação diferenciada. Esta clivagem corresponde à foliação principal, tanto nos sericita 
xistos e filitos quanto nos xistos tipo "Santa Rita"; nesta última unidade dispõe-se, de um modo geral, paralela ou subparalela à estratificação reliquiar dos metassedimentos.

A crenulação dessa foliação gera, por sua vez, uma nova clivagem mais espaçada e menos penetrativa.

A última superfície desenvolvida eqüivale à foliação definida pela orientação mineral provocada pela movimentação associada aos falhamentos transcorrentes.

As superfícies foram produzidas por quatro fases de deformação comprovadas, que deram origem, também, a dobras reconhecíveis meso e macroscopicamente.

GEOCRONOLOGIA Datações efetuadas por meio do método $\mathrm{Rb} / \mathrm{Sr}$, em rocha total, em amostras dos xistos da unidade rítmica "Santa Rita", forneceram idade de $750 \pm 20 \mathrm{Ma}$, com razão inicial de 0,7277 $\pm 0,0009$ (Vieira \& Tassinari 1988) - esta, interpretada como a época do primeiro evento de deformação, $\mathrm{F}_{1}$, sincrônico ao metamorfismo reginal progressivo $\mathrm{M}_{1}$.

Porém, como para seqüências litoestruturalmente semelhantes estudadas em detalhe no Paraná um número maior de datações indica valores transamazônicos (MMAJ/JICA 1982, Batolla Jr et al. 1981), é possível que a idade de $750 \pm 20 \mathrm{Ma}$, obtida para os "xistos Santa Rita", represente apenas o rejuvenescimento destas rochas no Brasiliano.

O Granito de Embu-Guaçu, datado pelo mesmo método, revelou idade de $612 \pm 83 \mathrm{Ma}$, com razão inicial de 0,707 $\pm 0,007$, que deve corresponder à época de colocação deste corpo nos níveis superiores da crosta. Um concentrado de moscovita de um pegmatite a ele associado, datado pelo método $\mathrm{K} / \mathrm{Ar}$, forneceu idade de $552 \pm 15 \mathrm{Ma}$, interpretada como a idade de formação da rocha.

EVOLUÇ̃̃O GEOLÓGICA Os dados obtidos permitem esboçar a evolução geológica das seqüências que afloram na região de Embu-Guaçu - Parelheiros (Fig. 3).

As transformações das unidades sedimentares tiveram início em torno de $750 \mathrm{Ma}$, com o metamorfismo regional progressivo $\mathrm{M}_{1}$, contemporâneo e tardio à primeira fase de deformação, $\mathrm{F}_{1}$, e anterior à segunda, $\mathrm{F}_{2}$. E dessa mesma época o magmatismo básico/ultrabásico que deu origem aos níveis intercalados aos "xistos Santa Rita".

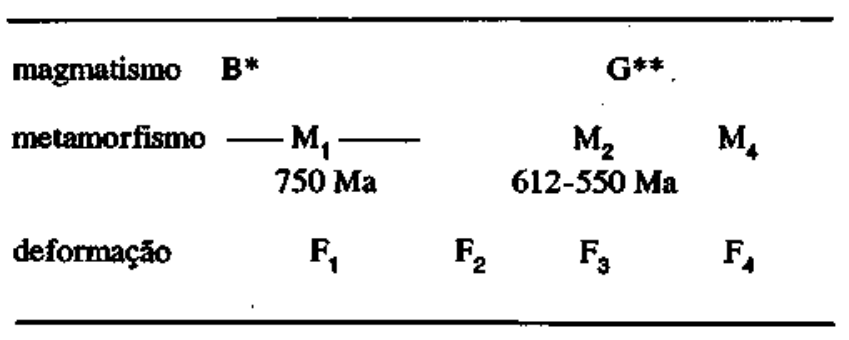

\section{* básico/ultrabásico}

* granftico

Figura 3 - Esbogo da evoluçāo geologica da regiăo de EmbuGuaçu-Parelheiros

Figare 3 - Outine of geological evolution of the Embu-Guactu - PareIletros Regios

O segundo evento de metamorfismo, interpretado como, pelo menos em parte, metassomático, foi imediatamente posterior à terceira fase de deformação, $F_{3}$, e à granitogênese responsável pela geraçãp dos Granitos de Parelheiros e EmbuGuaçu a $612 \pm 83 \mathrm{Ma}$.

O terceiro evento de metamorfismo, correspondente ao metamorfismo retrógrado, processou-se durante o resfriamento que se seguiu à colocação dos corpos graníticos.

Finalmente, os últimos episódios são materializados pelos falhamentos transcorrentes e pelo metamorfismo cataclástico a eles associados.

A constatação, mediante as observações de campo e petrográficas, de que não foram atingidas as condições de anatexia, não tendo sido gerados migmatitos verdadeiros, faz com que estas unidades sejam mais adequadamente posicionadas no Complexo Ectinítico Pilar, antes que no Complexo Migmatítico Embu, ambos do Grupo Açungui.

Agradecimentos Este trabalho teve o suporte financeiro da Fundação de Amparo à Pesquisa do Estado de São Paulo FAPESP (processo Geologia 85/0899-1) e do Conselho Nacional de Desenvolvimento Científico e Tecnológico - CNPq (processo 407051/87 - 2GL/FV).

\section{REFERÊNCIAS BIBLIOGRÁFICAS}

BATOLLA Jr, F.; SILVA, A.T.S.F. da; ALGARTE, J.P. 1981. O Pré-Cambriano da região sul-sudeste do Estado de São Paulo e este-nordeste do Estado do Paraná. In: SIMP. REG. GEOL., 3 , Curitiba, 1981. Atas... Curitiba, SBG. v.1, p.94-108.

BISTRICHI, C.A. 1982. Geologia do SincKnório de Ptrapora, SP. São Paulo. 92p. (Dissertação de Mestrado, IG/USP)

COUTINHO, J.M.V. 1972. Petrohgia do Pré-Cambriano de São Paulo e arredores. São Paulo, USP/IG. p. 5-99. (Boi. 3).

COUTINHO, J.M.V. 1980. Carta geológica da região metropolitana da Grande São Paulo em escala 1:1.000.000. Emplasa. Sec. Neg. Metropol., Gov. Estado de São Paulo.

HASUI, Y. \& SADOWSKI, G.R. 1976. Evolução geológica do Pré-Cambriano na região sudeste do Estado de São Paulo. Rev. Bras. Geoc. 6(3): 180-200.

HASUI, Y.; CARNEIRO, C.D.R.; BISTRICHI, C.A. 1978. Os granites e granitóides da regiẫo de dobramentos sudeste nos Estados de São Paulo e Paraná. In: CONGR. BRÁS. GEOL., 30, Recife, 1978. Anais... Recife, SBG. v.6, p.2594-2606.

LANDIM, P.M.B. coord. 1984. Mapa geológico do Estado de São Paulo, escala 1:250.000. Sec. de Obras e Meio Ambiente, DAEE, IGCE/UNESP.

METAL MINING AGENCY OF JAPAN. INTERNATIONAL COOPERATION AGENCY 1982. Report on geological survey of
Anta Gorda. Convênio DNPM/CPRM/MMAJ/JICA. Ill p. (Phase 2).

MORGENTAL, A.; BATOLLA Jr., F.; PINTO, G.G.; PAIVA, I.P.; DRUMOND, J.B.V. 1975. Projeto Sudelpa. Geologia. Convênio Sudelpa/CPRM. v. 1. (Rei. Final).

VIEIRA, S.R.S.S. 1989. Estudo Kto-estrutural da região de Embu-Guaçu - Parelheiros, São Paulo. São Paulo. 122p. (Dissertação de Mestrado, IG/USP).

VIEIRA, S.R.S.S. \& TASSINARI, C.C.G. 1988. Estudo petrológico e geocronologia das rochas da região de Embu-Guaçu, Estado de São Paulo. In: CONGR. BRÁS. GEOL., 35, Belém, 1988. Anais.. Belém, SBG. v.3, p.1391-1399.

WERNICK, E. 1984 Caracterização genética de alguns granitóides brasilianos dos Estados de São Paulo e Minas Gerais e implicações geotectônicas preliminares. In: CONGR. BRÁS. GEOL., 33, Rio de Janeiro, 1984. Anais... Rio de Janeiro, SBG. v.6, p.2902-2918.

MANUSCRITO A632 Recebido em 23 de novembro de 1989 Revisão do autor em 27 de dezembro de 1989 Revisão aceita em 28 de dezembro de 1989 